\title{
LOS MÉTODOS ALTERNATIVOS DE SOLUCIÓN DE CONTROVERSIAS Y SUS FACILITADORES EN EL SISTEMA PENAL ACUSATORIO MEXICANO: HACIA UNA JUSTICIA RESTAURATIVA, REPARACIÓN DEL DAÑO INTEGRAL Y REINSERCIÓN SOCIAL
}

\author{
The alternative methods of settlement of disputes and their facilitators in the mexican \\ accustive penal system: towards a restoring justice, repair \\ of comprehensive damage and social reinsurance
}

\author{
Christian Norberto HERNÁNDEZ AGUIRRE \\ Jessica MENDIVIL TORRES ${ }^{* *}$ \\ Cynthia Vedelí HERNÁNDEZ AGUIRRE $E^{* * *}$
}

\begin{abstract}
Sumario:
I. Introducción II. Inflexión entre los MASC, justicia restaurativa, reparación del daño integral y reinserción social III. Los MASC en materia penal y las funciones de sus facilitadores IV. Los facilitadores $y$ los delitos en que proceden los acuerdos reparatorios. Idoneidad y límites V. Conclusiones VI. Fuentes de información
\end{abstract}

Resumen: En este tema se analizan diversas perspectivas sobre los métodos alternativos de solución de controversias en materia penal en México y sus facilitadores en relación con una justicia restaurativa, reparación del daño integral y reinserción social ante posibles soluciones que se pueden generar ante la comisión o posible comisión de un delito, donde la resolución de controversias alternativas puede ser vista como un proceso creativo, generativo y transformador con la capacidad de desarrollar mejores soluciones y delimitada por derechos fundamentales.

Palabras clave: Métodos alternativos, Justicia restaurativa, reparación del daño y reinserción social.

\begin{abstract}
This article analyzes different perspectives on Alternative Methods of Dispute Resolution in criminal matters in Mexico and its facilitators in relation to restorative justice, reparation of the integral damage and social reintegration before possible solutions that can be generated before the commission or possible commission Of a crime, where alternative dispute resolution can be seen as a creative, generative and transformative process with the capacity to develop better solutions and delimited by fundamental rights.
\end{abstract}

\footnotetext{
*Profesor-investigador de la Universidad Autónoma de Baja California, Facultad de Ciencias Administrativas y Sociales, campus Ensenada, integrante del cuerpo académico "Estado de Derecho y Justicia" (UABC-CA-247) y miembro del Sistema Nacional de Investigadores, nivel I, christian8879@uabc.edu.mx.

** Profesor-investigador de la Universidad Autónoma de Baja California, Facultad de Ciencias Administrativas y Sociales, campus Ensenada, integrante del cuerpo académico "Estado de Derecho y Justicia" (UABC-CA-247), mendivilj@uabc.edu.mx.

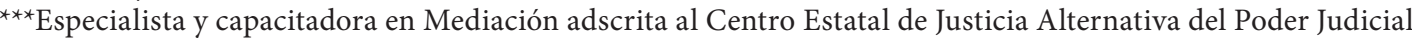
del Estado de Colima, vedeli77@hotmail.com.
} 
Christian Norberto Hernández Aguirre

Jessica Mendivil Torres

Cynthia Vedelí Hernández Aguirre

Keywords: Alternative Methods, Restorative Justice, Harm Redress and Social Reintegration.

\section{Introducción}

En el presente artículo no nos centraremos en un análisis meramente discursivo ni propagandístico en el que se exprese por qué son mejores los métodos alternativos de solución de controversias $^{1}$ que otros para descongestionar, desjudicializar o solucionar asuntos en materia penal, o sobre las bondades entre unos y otros MASC para preferir su empleo a la vía judicial ¿Es que son los MASC un mejor medio para una justicia restaurativa, reparación del daño y reinserción social?

Por lo anterior, se analizan perspectivas sobre los principios de los MASC que podrán progresar en materia penal y que son posibles en México. Retos para una justicia restaurativa que podría devenir posiblemente de su práctica (como por ejemplo, de la mediación) donde según Aguiló, los buenos argumentos (analizados desde la perspectiva pragmática) parecen compartir con las buenas ofertas el hecho de que cumplen la función de mover al receptor de ambos a consentir, a acordar'.

Se reflexiona entre la teoría y legislación actual relativa sobre los MASC en materia penal en México $^{3}$, entre lo que se persigue y propone mediante el empleo e impacto de alternativas para solucionar la problemática que se genera ante un delito. Se delibera sobre cómo los MASC (mediación, conciliación y junta restaurativa ${ }^{4}$ ) pueden contribuir a un proceso restaurativo ${ }^{5}$ creativo para la reparación del daño y hacia una reinserción social diversa a la prisión o desde la prisión.

Por otro lado, se analiza la figura del facilitador y su perfil, como la capacitación y experiencia que se necesita para su mejor desempeño, así como, para la posibilidad del seguimiento de los acuerdos por un órgano que ya se estipula en la legislación nacional, con lo que se ayude a la medición de su impacto, resultados y vigilancia continua en cuanto a su efectividad, no para su cumplimiento forzoso y no solo para observar la transmisión de mensajes y su culminación, sino también, para que se lleve un control y garantía de la transformación social que se busca me-

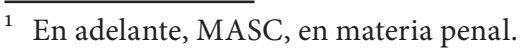

2 Aguiló Regla, Josep (2015) El arte de la mediación. Argumentación, mediación y negociación, Trotta, Madrid, p. 29.

3 Desde el artículo 17 de la Constitución Mexicana se analiza la justicia alternativa y la reparación del daño como una nueva vía o concepción del derecho penal. En lugar de la imposición de una pena corporal por la comisión de un delito, se establecen mecanismos que permiten el arreglo del conflicto a través de una justa reparación del daño causado a raíz de un delito. Es decir, la reparación del daño como una tercera vía jurisdiccional en el sistema penal mexicano. En Esparza Martínez, Bernardino (2015) La reparación del daño, INACIPE, México, D. F., p. 5 .

4 Estos tres métodos alternativos posibles en México, de acuerdo a la Ley Nacional de Mecanismos Alternativos de Solución de Controversias en Materia Penal. Actualizada a 29 de diciembre de 2014.

${ }^{5}$ En concordancia con Domingo de la Fuente, Virginia:
}

hay otras herramientas, más o menos restaurativas según incluyan a todos los afectados por el delito o solo algunos: conferencias restaurativas, círculos de paz, paneles de víctimas, servicios en favor de la comunidad, servicios de asistencia a las víctimas, programas de reparación del daño, comisiones para la verdad y la reconciliación, comités para la reparación del daño [...] Por eso, la Justicia Restaurativa es un concepto amplio, que incluye la filosofía, unos valores que la alimentan y conforman sus características básicas y una serie de herramientas que hacen realidad estos valores y esta filosofía.

Para mayor información véase Domingo de la Fuente, Virginia (2017) "Aproximación a la justicia restaurativa", p. 2, [en línea] disponible en: https://ddd.uab.cat/pub/eciejur/eciejur_a2017n1/eciejur_a2017n1a3.pdf. [fecha de consulta 18 de marzo de 2017]. 
diante su enfoque u orientación constructivista, que lleve a la recuperación del poder, reconocimiento del conflicto y concientización ${ }^{6}$, así como a vivir en armonía en beneficio de la sociedad.

\section{Inflexión entre los MASC, justicia restaurativa, reparación del daño integral y reinserción social}

En este apartado se comprenden principios y posibles alcances que podrán cumplir los MASC en materia penal en relación con los conceptos de justicia restaurativa ${ }^{7}$, reparación del daño ${ }^{8}$ y reinserción social ${ }^{9}$. Siendo que, dentro de las finalidades de la justicia restaurativa, en palabras de Hernández, son el hecho que el victimario, al ser un miembro de la sociedad, no sea excluido, porque esto implica un perjuicio a los intereses y la estabilidad del mismo grupo. Lo que es mejor para esta teoría es la forma de solución, la reparación del daño por parte del infractor del daño causado y su rehabilitación para restablecer los lazos entre el autor del delito, la víctima y la comunidad ${ }^{10}$. Por lo que se aduce, que los MASC son un medio más y no el único para su

\footnotetext{
6 Si el modelo popular de la transmisión es compatible con el enfoque de resolución de problemas, la orientación construccionista social se amolda mejor al enfoque transformador. El modelo de la transmisión se centra en la generación de mensajes que lleven al acuerdo; el modelo construccionista social se centra en la transformación de uno mismo, el otro y la situación. Bush y Folger han caracterizado como los objetivos centrales del enfoque transformador a la recuperación de poder (empowerment) y el reconocimiento de los demás.

La recuperación del poder es la capacidad de cada individuo para identificar sus preocupaciones, evaluar sus opciones y adoptar decisiones bien informadas.

El reconocimiento es la capacidad de cada individuo para comprender a los demás, respetarlos y mostrarles consideración.

La concientización (awareness) es la habilidad de cada individuo para ampliar los alcances de su comprensión descubriendo nueva información, estableciendo nuevas conexiones y desarrollando nuevas formas de percibir su situación y de operar en ella. SHAILOR, Jonathan G. "Desarrollo de un enfoque transformador para la mediación: consideraciones teóricas y prácticas” en Fried Schnitman, Dora (comp. 200o), Nuevos paradigmas en la resolución de conflictos. Perspectivas y prácticas, Ediciones Granica S. A. Buenos Aires, Argentina, p. 192.

7 La justicia restaurativa representa una filosofía para entender el conflicto penal en el esquema del pensamiento y las estrategias para ponerlo en práctica. Hernández Álvarez, Martha (2010), “Justicia restaurativa” en Moreno Vargas, Mauricio, Nuevo Sistema de Justicia Penal para el Estado de México, Porrúa, México, D. F. p. 131. Una forma de llevarse a cabo esta nueva filosofía de Justicia es en la Mediación, y en general se puede decir que es un procedimiento en el cual, las partes, ayudadas por un tercero (mediador) que no tiene facultades de decisión, intentan resolver un conflicto. El mediador o facilitador sirve de cauce para que víctima y ofensor puedan llegar a acuerdos de restauración y reparación del daño y también para que el infractor asuma su responsabilidad por el hecho cometido. Véase Domingo de la Fuente, Virginia (2008) Justicia restaurativa y mediación penal, p. 14. [en línea] disponible en: http://www.justiciarestaurativa.org/news/justicia-restaurativa-y-mediacion-penal, [consulta 21 de marzo de 2017].

8 La reparación del daño es más bien, la solución objetiva o simbólica que restituye la situación al estado anterior a la comisión del delito, satisfaciendo a la víctima, pudiendo ser la devolución de la cosa hurtada, una disculpa pública o privada, trabajo gratuito, etc. Cesano, José Daniel (2007), "Reparación y Resolución del Conflicto Penal: Tratamiento en el Código Penal Argentino y perspectivas en el proyecto de reforma integral 2006” en Marchiori, Hilda (coord. 2007), Principios de Justicia y Asistencia para las Víctimas. Estudios sobre la Victimización editorial Encuentro, Argentina, p. 139.

9 La integración social se refiere al proceso de integrarse social y psicológicamente en el entorno social. Sin embargo, en los campos de prevención del delito y justicia penal, en donde se la usa con frecuencia, el término se refiere más específicamente a las diversas formas de intervención y programas individuales para evitar que se vean involucrados en conductas delictivas o, para aquellos que ya están en conflicto con la ley, para reducir la probabilidad de que vuelvan a delinquir. Oficina de las Naciones Unidas contra la Droga y el Delito (2013), Guía de introducción a la prevención de la reincidencia y la reintegración social del delincuentes, Serie de Guías de Justicia Penal, Nueva York, p. 6, [en línea] disponible en: https://www.unodc.org/documents/justice-and-prisonreform/UNODC_SocialReintegration_ESP_LR_final_online_version.pdf. [consulta 11 de mayo de 2017.]

10 Hernández Álvarez, Martha, op. cit., nota 7, p. 137.
} 
Christian Norberto Hernández Aguirre

Jessica Mendivil Torres

Cynthia Vedelí Hernández Aguirre

progreso pero que sí podrían ayudar a generar más y, en ocasiones, mejores soluciones a solamente emplear la vía judicial.

Lo que nos lleva a comprender que el concepto de reparación del daño ante un delito abre las posibilidades de cambio y de generación de soluciones a problemáticas penales, si se percibe a la pena no solamente como la única consecuencia o único medio para restaurar, rehabilitar y resarcir a una víctima e infractor, respectivamente. Se aduce que los fines de la justicia restaurativa se pueden cumplir tanto por medio de los MASC, por la vía judicial, cuanto mediante acciones propuestas de política criminal, entre medios, métodos o acciones dependiendo su finalidad (como por ejemplo, en España, la reparación del daño a la víctima por el culpable o la disminución de sus efectos por el mismo funciona como atenuante de la responsabilidad criminal, siendo posible hasta antes de la celebración del juicio oral ${ }^{11}$ ).

Retomando el concepto de justicia restaurativa, para Zehr es un proceso a través del cual el infractor, con remordimientos por su conducta, acepta su responsabilidad hacia quien ha dañado y hacia la comunidad, que en respuesta a ello permite la reintegración del ofensor en la comunidad. El énfasis se pone en la restauración: restauración del ofensor en términos de auto-respeto, restauración de la relación entre la víctima y el ofensor, y también restauración de ambos dentro de la comunidad ${ }^{12}$. Por lo que además de los intervinientes se tiene que pensar en los beneficios que se logran para la sociedad, como el restablecimiento de la armonía hasta el ahorro de recursos en sentido amplio.

Dentro de los principios que se pueden relacionar a los MASC en materia penal en México, dirigidos a los intervinientes y al procedimiento que se sigue, se pueden mencionar los que se expresan en la Ley Nacional de Mecanismos Alternativos de Solución de Controversias en Materia Penal de México, como: I. Voluntariedad II. Información III. Confidencialidad IV. Flexibilidad y simplicidad V. Imparcialidad VI. Equidad y VII. Honestidad ${ }^{13}$. Varios de estos principios pueden coincidir con los que se persiguen mediante otros métodos, pero en particular con el empleo de alguno de los MASC, en donde se hace necesario que a su facilitador se le exija tener ciertas habilidades para el mejor desarrollo y culminación de los mismos y se generen soluciones, como por ejemplo, el tener empatía ${ }^{14}$, resiliencia ${ }^{15}$ y se comunique con asertividad ${ }^{16}$, entre

${ }^{11}$ Cfr. Artículo 21.5 de la Ley Orgánica 10/1995, de 23 de noviembre, del Código Penal de España.

${ }^{12}$ ZeHr, Howard (1990), Changing Lenses: A New Focus for Crime and Justice, en Olalde, Alberto (2006) Justicia Restaurativa y mediación en el ámbito penal. Apuntes Máster de mediación familiar y social de la Universidad de Murcia, 2006, p. 6 [en línea] disponible en: http://servicios.educarm.es/templates/portal/ficheros/websDinamicas/102/APUNTES\%20ALBERTO\%20OLALDE\%5b1\%5d\%5b1\%5d_1.pdf

${ }^{13}$ Artículo $4^{\circ}$ de la Ley Nacional de Mecanismos Alternativos de Solución de Controversias en Materia Penal. Actualizada a 29 de diciembre de 2014.

${ }^{14}$ La empatía es la capacidad de entrar, afectiva y emotivamente, en la realidad de otra persona, entender sus necesidades y expectativas, comprender su situación tal como la vive. Véase Mondragón-LASAGABaster, Jasone (2012), La Mediación en el Ámbito Penal/Criminológico. Tema 7. Habilidades y estrategias de comunicación en el proceso de mediación (curso 2012-2013), Universidad de Alicante, pp. 1-15, [en línea] disponible en: http://rua.ua.es/ dspace/handle/10045/25661

${ }^{15}$ La resiliencia es una actitud indispensable en la persona mediadora ya que es la que nos permitirá abordar las circunstancias y vivencias de las personas con las que vamos a mediar, de manera positiva, creativa y constructiva. La resiliencia es una actitud que se adquiere a través del adiestramiento de la mirada, para mirar la realidad trascendiendo el determinismo y haciéndonos capaces de cambiarla en libertad. De nuestra capacidad de resiliencia dependerá el que sepamos dar a cada persona la oportunidad de construir su propio futuro. Ibídem, pp. 13-14.

Así mismo, en el diccionario de la Real Academia Española se define en su primera acepción como capacidad de adaptación de un ser vivo frente a un agente perturbador o un estado o situación adversos, [en línea] disponible en: http://dle.rae.es/srv/search?m=30\&w=resiliencia.

${ }^{16}$ En Pacheco Pulido, Guillermo (2015), Mediación. Cultura de paz, medio Alternativo de administración de justicia, Porrúa, México, $3^{\mathrm{a}}$ ed., p. 19. Se define a la asertividad "como la habilidad para transmitir un lenguaje claro 
otras habilidades. Asimismo, el respeto a la autonomía individual es fundamental para llegar a un acuerdo o pacto donde, en concordancia con Aguiló, su validez procede -como es sabido- del hecho de que son expresión del ejercicio de la autonomía de los sujetos que participan. Por ello, los pactos son siempre voluntarios ${ }^{17}$, ya que sin autonomía de la víctima y victimario, simplemente no se puede dar un pacto o puede no existir o ser nulo.

Por otro lado, dentro del artículo 10 de la ley nacional de MASC en materia penal, se hace posible que en su

Derivación. El Ministerio Público, una vez recibida la denuncia o querella orientará al denunciante o querellante sobre los Mecanismos Alternativos de solución de controversias y le informará en qué consisten éstos y sus alcances. El Ministerio Público, podrá derivar el asunto al Órgano adscrito a las procuradurías ofiscalías cuando la víctima u ofendido esté de acuerdo con solicitar el inicio del Mecanismo Alternativo [...]

Lo anterior sin sacrificar la posibilidad de los MASC, a los que quizás no se pueda llegar ante una posible amenaza de una pena o medida de seguridad por alguna autoridad (como por ejemplo, por el órgano que podría derivarlo). Ya que no se deberá forzar el acudir a los mismos como tampoco el llegar a un convenio sea quien sea el facilitador.

Sobre la posibilidad de que haya diversos servidores públicos que puedan ayudar a su derivación, en el último párrafo del numeral 10 de la ley nacional de MASC en materia penal se expresa la posibilidad de que pueda ser hecha por un Juez de Control, como:

cuando el imputado haya sido vinculado a proceso, el Juez derivará el asunto al Órgano respectivo si el imputado y la víctima u ofendido están de acuerdo en solicitar el inicio del Mecanismo Alternativo previsto en esta Ley y se cumplan los requisitos de oportunidad y procedencia.

Inclusive, aunque no se considere necesario que el juez de control o MP pueda señalar una fecha para la celebración de una sesión de MASC, será posible hacerlo sin que se persiga un atraso sino una mejor explicación de los alcances por un especialista.

Por otro lado, de acuerdo al artículo $6^{\circ}$ de la ley nacional de MASC referida, la oportunidad de acudir o aplicar los mismos podría ser "desde el inicio del procedimiento penal y hasta antes de dictado el auto de apertura a juicio o antes de que se formulen las conclusiones, según corresponda." Sin embargo, se aduce que es posible y pertinente acudir dentro de cualquier etapa del proceso judicial dependiendo su finalidad. Inclusive, en algunas entidades federativas mexicanas, ya se había legislado y hecho posible acudir a los MASC en cualquier etapa del proceso, como por ejemplo, después de terminado el mismo para la reparación del daño ${ }^{18}$.

Por ejemplo, en la Ley de Mecanismos Alternativos de Solución de Controversias para el Estado de Sonora se dispuso en su Artículo $9^{\circ}$ que en materia penal, habiéndose dictado sentencia

y positivo, con la capacidad de percibir el contenido de cualquier expresión oral, corporal, o escrita que refleje los sentimientos, creencias y opiniones.

17 Aguiló Regla, Josep, op. cit. nota 2, p. 119.

${ }^{18}$ La justica alternativa pudiera ser factible en diversas fases, una pre procesal (como puede ser, antes de comenzar una denuncia o querella a lo que deviene una etapa de investigación, en la que pudiera también proponerse o derivarse de la misma), intra procesal (después de trabada la litis ante el juez, como excepción propuesta en el juicio por la parte interesada, como una vez impuesta la pena o medida de seguridad por el Estado, lo que puede afectar a la ejecución de lo juzgado en favor de las partes y sociedad), otra extra procesal (como puede ser, con convenios o acuerdos celebrados ante un Centro de Justicia Alternativa de cada entidad federativa) y, otra endo 
Christian Norberto Hernández Aguirre

Jessica Mendivil Torres

Cynthia Vedelí Hernández Aguirre

firme, sólo podrán tratar lo conducente a la reparación del daño. Asimismo, se puede observar en la Ley de Justicia Penal Alternativa del Estado de Querétaro, que se sigue dentro del Artículo $2^{\circ}$, en que se disponía la posibilidad de: acceder a ellos en cualquier etapa del procedimiento, incluso después de que la sentencia dictada haya causado ejecutoria, pero en este caso, sólo se podrá tratar lo conducente a la reparación del daño. Como también en la Ley de MASC del estado de Yucatán, donde se dispuso en su artículo 12, que: En materia penal, habiéndose dictado sentencia firme, sólo se podrá tratar lo conducente a la reparación del daño y el Ejecutivo proveerá lo necesario para facilitar el encuentro de la víctima con el victimario a fin de hacer efectiva la justicia restaurativa.

Respecto al objeto y elementos que comprende un proceso restaurativo y que se puede alcanzar mediante el empleo de los MASC, de acuerdo con la Organización de las Naciones Unidas, se debe tomar en cuenta que:

hay al menos cuatro elementos básicos para que un proceso completamente restaurativo alcance sus objetivos: (a) una víctima identificable; (b) la participación voluntaria de la víctima; (c) un delincuente que acepte la responsabilidad de su comportamiento delictivo; y (d) la participación no forzada del delincuente. La mayoría de los métodos restaurativos se esfuerzan por alcanzar una dinámica interactiva especifica entre las partes involucradas. La meta es crear un ambiente sin enemistad ni amenaza en que los intereses y las necesidades de la víctima, del delincuente, de la comunidad y de la sociedad puedan ser atendidos ${ }^{19}$.

Partiendo de que la justicia restaurativa se centra en la reparación del daño, en proteger al condenado, resocializarlo, entre otras finalidades, más que en castigarlo para retribuir -como se venía dando en el sistema penal inquisitivo-mixto-, una justicia retribucionista centrada en la pena y medidas de seguridad (preferiblemente superada), al considerarse un método donde prevalece la prisión y sanciones pecuniarias -como un acto de venganza ${ }^{20}-$, se aduce que con la justicia restaurativa no se debe excluir ni a la víctima ni al victimario, como tampoco la posibilidad de encontrar acciones concretas e indicadores para hacerla posible mediante el empleo de variadas medidas o formas menos graves que las empleadas normalmente mediante un sistema dualista de penas y medidas de seguridad para pasar a una tercera vía, donde se incluya la reparación del daño, así como a la utilización de métodos alternativos como una opción más para el mejor progreso de derechos humanos y fundamentales.

Asimismo, se reconoce que de acuerdo a estándares generados internacionalmente las víctimas de violaciones a derechos humanos tienen derecho a recibir una reparación del daño ade-

o post procesal (que pudiera suceder, una vez que se está ejecutando la sentencia) con lo que se puede hacer posible la armonización de intereses, principios y valores en diversos momentos. Para mayor información, véase Hernández Aguirre, Christian Norberto et al (2015), "Importancia de los métodos alternativos de solución de controversias en materia penal en México" en Revista Ciencia Jurídica, Año 4, No. 7, Universidad de Guanajuato, México, p. 8o.

${ }^{19}$ Organización de las Naciones Unidas (2006) Manual sobre programas de justicia restaurativa, Naciones Unidas, Nueva York, serie de manuales sobre justicia penal, p. 8. En línea. Disponible en: https://www.unodc.org/documents/justice-and-prison-reform/Masereconocenual_sobre_programas_de_justicia_restaurativa.pdf. Fecha de consulta: 21 de marzo de 2017.

${ }^{20}$ Así en SAmpedro-Arrubla, Julio Andrés (2010) "La justicia restaurativa: una nueva vía, desde las víctimas, en la solución al conflicto penal", 17 International Law, Revista Colombiana de Derecho Internacional, p. 92, [en línea] disponible en: http://www.scielo.org.co/pdf/ilrdi/n17/n17ao4.pdf.

Así mismo, en Villareal Sotelo, Karla, "La víctima, el victimario y la justicia restaurativa" en Rivista di Criminologia, Vittimologia e Sicurezza - Vol. VII - N. 1 - Gennaio-Aprile, Bologna, Italia, 2013, p. 45, [en línea] disponible en: http://eprints.bice.rm.cnr.it/4634/1/articolo_villarrealsotelo_2013-01.pdf. 
cuada, integral y proporcional a la naturaleza del acto violatorio y del derecho conculcado en la que se contemple, mediante una resolución judicial, una justa indemnización ${ }^{21}$, rehabilitación, restitución, satisfacción y medidas de no repetición ${ }^{22}$. Pero en el caso del empleo de los MASC, más que una proporcionalidad entre el hecho y el castigo, se debe analizar o contribuir a generar diversas y mejores soluciones más que un castigo que podrá propiciar otro conflicto costoso o que afecte a otros derechos humanos en mayor medida.

Asimismo, los MASC pueden ayudar a generar la materialización de una restauración, inserción o reinserción y reparación del daño, sin excluir a otros métodos que lo pueden hacer posible y sin recaer solamente en un sistema proporcionalista. En palabras de Cid Moliné, las alternativas (rehabilitadoras) a la prisión suponen una resolución del conflicto generado por el delito que, en principio, responde a dos de las objeciones señaladas al paradigma proporcionalista (su excesivo compromiso con la pena de prisión y el atribuir un rol secundario a la rehabilitación del/a delincuente), la justicia restauradora proporciona, en principio, una respuesta a las tres objeciones, por cuanto da un papel central a la víctima en la resolución del conflicto, a la vez que privilegia respuestas distintas a la prisión y procura la rehabilitación del/a delincuente ${ }^{23}$.

En palabras de Fried, el enfoque generativo incorpora al tratamiento de los conflictos una ecología de la virtualidad, aquello que es posible pero no existe aún. Es un emprendimiento que, desde la diversidad y la diferencia, construye una gama de prácticas y significados entre lo que es y lo que podría ser. Mediante el trazado de cada itinerario singular, el proceso de resolución alternativa de conflictos proyecta caminos posibles en un futuro, explora las bifurcaciones, las múltiples alternativas y utiliza las variaciones y la aleatoriedad para crear novedad. En el proce-

\footnotetext{
${ }^{21}$ Siendo que, en cuanto a la indemnización para una reparación del daño, la Suprema Corte en México ha aducido en jurisprudencia que: El derecho citado es un derecho sustantivo cuya extensión debe tutelarse en favor de los gobernados, por lo que no debe restringirse innecesariamente. Así, el daño causado es el que determina la naturaleza y el monto de la indemnización, de forma que las reparaciones no pueden implicar enriquecimiento ni empobrecimiento para la víctima o sus sucesores; además, no se pretende que la responsabilidad sea excesiva, ya que debe subordinarse a requisitos cualitativos.

Por otro lado, una indemnización será excesiva cuando exceda del monto suficiente para compensar a la víctima, sin embargo, limitar la responsabilidad fijando un techo cuantitativo implica marginar las circunstancias concretas del caso, el valor real de la reparación o de la salud deteriorada; esto es, una indemnización es injusta cuando se le limita con topes o tarifas, y en lugar de ser el Juez quien la cuantifique justa y equitativamente con base en criterios de razonabilidad, al ser quien conoce las particularidades del caso, es el legislador quien, arbitrariamente, fija montos indemnizatorios, al margen del caso y de su realidad. Tesis: 1a. /J. 31/2017 (10a.), Semanario Judicial de la Federación y su Gaceta, Décima Época, t. I, abril de 2017, p. 752.

Donde se coincide en cuanto a que al señalar topes en cuanto a la indemnización se podría sobre limitar una reparación del daño, lo que quizás del análisis e interpretación del caso en concreto puede variar, como variar las posibles acciones para hacerla posible integralmente sin estar sujeto únicamente a una indemnización y mucho menos a un tope económico.

${ }^{22}$ Comisión de Derechos Humanos del Distrito Federal (2010), Revista de Derechos Humanos, número 12, año VIII, p. 5, [en línea] disponible en: http://cdhdf.org.mx/wp-content/uploads/2014/o5/dfensor_12_2010.pdf. Por otro lado, la Corte Interamericana de Derechos Humanos en el caso "campo algodonero", recuerda que "el concepto de reparación integral (restitutio in integrum) implica el restablecimiento de la situación anterior y la eliminación de los efectos que la violación produjo, así como una indemnización como compensación por los daños causados. Corte IDH, Caso González y Otras (Campo Algodonero) vs. México, párr. 450.

23 Cid Moliné, José (2009), "Medios alternativos de solución de conflictos y derecho penal”, en Revista Estudios de la Justicia, No. 11, Chile, p.122. En línea. Disponible en: http://web.derecho.uchile.cl/cej/rej11/CID\%2O_11_.pdf
} 
Christian Norberto Hernández Aguirre

Jessica Mendivil Torres

Cynthia Vedelí Hernández Aguirre

so, los participantes construyen conjuntamente nuevas posibilidades, entramando los problemas presentados, las acciones y los conocimientos ${ }^{24}$.

Por otro lado, con la expedición de la ley nacional de ejecución penal en México, se hace posible un proceso restaurador mediante el empleo de los MASC, como por ejemplo, el empleo de la mediación en particular y respectivamente desde la prisión, ya que podría ser la prisión el punto de partida o donde comienza otro conflicto y oportunidad para resolverlo o reconducirlo a una mejor solución mediante el empleo de alguno de los MASC. En el artículo 200, de la Ley Nacional de Ejecución de Sanciones Penales (LNESP) se expresa que, como puede suceder mediante una mediación, conciliación o junta restaurativa:

En la ejecución de sanciones penales podrán llevarse procesos de justicia restaurativa, en los que la víctima u ofendido, el sentenciado y en su caso, la comunidad afectada, en libre ejercicio de su autonomía, participan de forma individual o conjuntamente de forma activa en la resolución de cuestiones derivadas del delito, con el objeto de identificar las necesidades y responsabilidades individuales y colectivas, así como a coadyuvar en la reintegración de la víctima u ofendido y del sentenciado a la comunidad y la recomposición del tejido social.

En el numeral 206 de la legislación nacional (LNESP), se establece como una posibilidad la utilización de uno de los MASC de la siguiente manera:

Mediación penitenciaria. En todos los conflictos inter-personales entre personas privadas de la libertad o entre ellas y el personal penitenciario derivado del régimen de convivencia, procederá la Mediación Penitenciaria entendida como el proceso de diálogo, auto-responsabilización, reconciliación y acuerdo que promueve el entendimiento y encuentro entre las personas involucradas en un conflicto generando la pacificación de las relaciones y la reducción de la tensión derivada de los conflictos cotidianos que la convivencia en prisión genera. Para su aplicación, se seguirán las disposiciones contenidas en esta Ley, el Protocolo correspondiente y en la Ley Nacional de Mecanismos Alternativos de Solución de Controversias en Materia Penal.

Siendo que, ante la imposición de una pena prevalece actualmente la prevención especial, donde debiera perseguirse la reeducación y resocialización digna de la persona que cometió un delito, al contrario de penas o supuestas soluciones que atentan contra la misma.

En concordancia con Pastor y Huertas, se considera que la mediación (como el empleo de diversos MASC) podría ser un camino para el aprendizaje de valores útiles, destacando la responsabilización de estos en sus actos, para no ver el sistema penitenciario como un mero castigador de conductas sino con una posibilidad de cambio para no repetir éstas, jurídicamente viable ${ }^{25}$. Como al perseguir el mismo fin antes de un proceso judicial que implique posiblemente una mayor probabilidad o dinámica para llegar a una mejor solución, que no solamente lleve a la lesión de otro u otros bienes jurídicos, como la libertad o dignidad sin resultar necesario.

\footnotetext{
${ }^{24}$ Fried Schnitman, Dora, op. cit., nota 7, pp. 137-138.

25 Pastor Seller, Enrique y Huertas Pérez, Elena (2012) “La mediación penitenciaria como método alternativo de resolución de conflictos entre internos en el ámbito penitenciario”, en Revista Entramado, vol. 8, núm. 2, julio-diciembre, p. 152. En línea, disponible en: http://www.redalyc.org/articulo.oa?id=265425848009
} 


\section{Los MASC en materia penal y las funciones de sus facilitadores}

En México, son tres los MASC reconocidos actualmente en la ley nacional de MASC en materia penal, entre ellos, la mediación, la conciliación y la junta restaurativa. Cabe mencionar que en estos mecanismos es necesario que ocurran tres cosas entre los participantes:

1. El reconocimiento y/o aceptación por parte del ofensor de haber cometido el ilícito a la víctima.

2. La aceptación de participar en el proceso, entendiéndola de manera voluntaria, lejos de coacción física o psicológica.

3. Todo ello, previa evaluación del ofensor y víctima que se sienta seguro al momento de participar.

Siendo que el facilitador que conduzca los MASC deberá asegurarse de tales cuestiones utilizando las sesiones por separado, empezando por la víctima para después pasar con el ofensor y, en su caso, tener sesiones conjuntas con ellos y con las víctimas indirectas. Tenemos que tener claro que mediación y conciliación, como se establece en los Arts. 21 y 25, respectivamente, de la Ley Nacional se diferencian de la siguiente manera:

Mediación: Es el mecanismo voluntario mediante el cual los Intervinientes, en libre ejercicio de su autonomía, buscan, construyen y proponen opciones de solución a la controversia, con el fin de alcanzar la solución de ésta. El Facilitador durante la mediación propicia la comunicación y el entendimiento mutuo entre los Intervinientes.

Conciliación: Es el mecanismo voluntario mediante el cual los Intervinientes, en libre ejercicio de su autonomía, proponen opciones de solución a la controversia en que se encuentran involucrados.

Además de propiciar la comunicación entre los Intervinientes, el Facilitador podrá, sobre la base de criterios objetivos, presentar alternativas de solución diversas.

Teniendo en cuenta que la diferencia entre uno y otro mecanismo alternativo radica que en la mediación, quien funge como mediador no propone soluciones, solamente trabaja con las propuestas que establecen las partes y, que en la conciliación, el facilitador sí podrá proponer alguna solución, observando en todo momento que su intervención sea sin olvidar los principios básicos de los MASC y distinguiendo, en caso de ser el mismo facilitador (mediadorconciliador), cuándo es que se emplea tal o cual método para que el destinatario esté consciente de su función. Por otro lado, en relación a las juntas restaurativas que se contemplan en el art. 27 de la Ley Nacional, a la letra se definen como:

el mecanismo mediante el cual la víctima u ofendido, el imputado y, en su caso, la comunidad afectada, en libre ejercicio de su autonomía, buscan, construyen y proponen opciones de solución a la controversia, con el objeto de lograr un Acuerdo que atienda las necesidades y responsabilidades individuales y colectivas, así como la reintegración de la víctima u ofendido y del imputado a la comunidad y la recomposición del tejido social.

Por lo que en una junta restaurativa intervienen el ofensor, la víctima y comunidad afectada, entre ellos los familiares de las partes, requiriéndose una metodología y profesionalización del facilitador de dicho proceso restaurativo, donde el facilitador también podrá presentar propuestas para solucionar el conflicto como en la conciliación pero incluyente. En ese sentido, 
Christian Norberto Hernández Aguirre

Jessica Mendivil Torres

Cynthia Vedelí Hernández Aguirre

se confía que mientras se encuentren además de la víctima, ofensor y otras personas afectadas, tal es el caso de familiares u otras personas relacionadas al conflicto, a consideración y guía del facilitador especializado, siguiendo en todo momento el principio de la voluntariedad, el resultado del proceso y acuerdo, deberá pretender ser restaurador.

Debemos resaltar que en el artículo 29 de la ley nacional de MASC en materia penal se expresan algunos alcances de la junta restaurativa, una vez aprobado un acuerdo, y que a la letra dice:

\section{[...] La Reparación del daño derivada de la junta restaurativa podrá comprender lo siguiente:}

I. El reconocimiento de responsabilidad y la formulación de una disculpa a la víctima u ofendido en un acto público o privado, de conformidad con el Acuerdo alcanzado por los intervinientes, por virtud del cual el imputado acepta que su conducta causó un daño;

II. El compromiso de no repetición de la conducta originadora de la controversia y el establecimiento de condiciones para darle efectividad, tales como inscribirse y concluir programas o actividades de cualquier naturaleza que contribuyan a la no repetición de la conducta o aquellos programas específicos para el tratamiento de adicciones;

III. Un plan de restitución que pueda ser económico o en especie, reparando o reemplazando algún bien, la realización u omisión de una determinada conducta, la prestación de servicios a la comunidad o de cualquier otra forma lícita solicitada por la víctima u ofendido y acordadas entre los Intervinientes en el curso de la sesión.

En dicho numeral se observa la intención del legislador de poder ver más integral la reparación del daño, es decir, más allá de lo económico está el reconocimiento de la comisión del hecho ilícito, la seguridad, el compromiso, ya sea, la no repetición de la conducta no lícita, como también sus consecuencias en lo económico o en especie. Es por ello que el Estado debe poner énfasis en el perfil de quien conduce estos métodos y la capacitación de los facilitadores sin que quede como letra muerta, puesto que se pone en riesgo a las bondades de nuestro sistema penal acusatorio mexicano. Desde luego, enfocarse en encomendar tal noble tarea y función a las personas que realmente cumplan con un perfil y una profesionalización (capacitación- experiencia) podemos y pugnamos que su resultado sea hacia una reparación como solución más integral.

Cabe señalar que con esta visión de hacer más integral el procedimiento, el Estado debe de preocuparse, además de tener un facilitador especializado, que haya un órgano de seguimiento que realmente cumpla con los fines que marca la ley $\mathrm{Nacional}^{26}$, así como una amplia coordinación de todas las autoridades que se relacionan con este sistema acusatorio y la realización de

\footnotetext{
${ }^{26}$ Así se incluye este órgano dentro del artículo 36 de la ley nacional de MASC: “Área de seguimiento. El Órgano contará con un área de seguimiento, la cual tendrá la obligación de monitorear e impulsar el cumplimiento de los Acuerdos alcanzados por los Intervinientes en el Mecanismo Alternativo. El seguimiento podrá consistir en:

I. Apercibimiento a los Intervinientes para el caso de incumplimiento del Acuerdo;

II. Visitas de verificación;

III. Llamadas telefónicas;

IV. Recepción o entrega de documentos, pagos, bienes u objetos;

$V$. Citación de los Intervinientes y demás personas que sean necesarias;

VI. Envío de correspondencia o comunicación, pudiendo usar medios electrónicos, y

VII. Cualquier otra medida necesaria para el cumplimiento del Acuerdo de conformidad con los principios y disposiciones establecidas en esta Ley.
} 
una base de datos que pueda ayudar a su mejor operatividad y medición de su impacto para la concientización de la sociedad sobre sus beneficios.

Por otro lado, y en particular sobre la figura del facilitador, visto de manera general, se considera como la persona especializada que cumple con los requisitos que por ley son necesarios (perfil-capacitación en horas) y que, por ende, es el encargado de hacer funcionar y facilitar el proceso restaurador más conveniente, según sea el caso, ya sea a través de la mediación, conciliación o junta restaurativa, con lo que se procure resolver el conflicto que se presente en materia penal. Se aduce que con este sistema de justicia acusatorio, con especial referencia a México, se incorporan tres MASC con los que se busca dar una opción más para una justicia restaurativa o ser medios de gestión para las personas que se encuentran ante un conflicto penal para resolverlo de la mejor manera posible, ponderando (según sea el caso) la posibilidad del diálogo voluntario para generar su solución.

Entendemos que para el Estado es de suma importancia la aplicación de los MASC al incorporarlos como un camino más, fuera o dentro de un procedimiento judicial, y que éstos sirvan a un desfogue de asuntos judiciales que sean menos costosos y como una opción más hacia un resultado restaurativo. En concordancia con la Organización de las Naciones Unidas, los Estados que estén el en proceso de implementar procesos restaurativos no deben olvidar los principios básicos sobre la utilización de programas de justicias restaurativas en materia penal, donde se define un proceso restaurativo como: todo aquél proceso en que la víctima, el delincuente y, cuando proceda cualesquiera otras personas o miembros del comunidad afectados por un delito participen conjuntamente de forma activa en la resolución de las cuestiones derivadas del delito con ayuda de un facilitador ${ }^{27}$.

Tal es el caso que en la aplicación de los MASC para una justicia restaurativa, los Estados deben de poner énfasis en que son una forma de responder al comportamiento delictivo, balanceando las necesidades de la comunidad, de las víctimas y de los delincuentes ${ }^{28}$. Se trata de que todas las partes escuchen su sentir, sus necesidades relativas al conflicto planteado y la forma en que les ha repercutido en su vida desde que ocurrió la comisión de un delito, sin olvidar la forma en cómo a cada una de las partes le gustaría resolver el conflicto: a la víctima qué se le reparará y al ofensor de qué manera se podría resocializar.

Una definición generalmente aceptada de justicia restaurativa es aquélla proporcionada por Tony Marshall: la justicia restaurativa es un proceso a través del cual las partes o personas que se han visto involucradas y/o que poseen un interés en un delito en particular, resuelven de manera colectiva la manera de lidiar con las consecuencias inmediatas de éste y sus repercusiones para el futuro ${ }^{29}$. No necesariamente con los MASC se puede hacer posible lo anterior, pero son una buena oportunidad.

Por otro lado, la verdadera elección y profesionalización de los operadores van a dar la pauta para que el empleo de los MASC sea lo más cercano a cumplir con los objetivos de todo programa que tenga la finalidad de lograr una reparación integral. Es decir, no solo hablar de una reparación económica, sino responder a las verdaderas necesidades de las personas enfrascadas en un conflicto penal y dar un espacio para conocer los temas subyacentes del conflicto con la ayuda de un facilitador, en donde puedan interactuar de manera respetuosa la víctima, delincuente y las personas que han resultado afectadas, llegando a ello, sin olvidar el principio de

\footnotetext{
27 Organización de las Naciones Unidas, op. cit., nota 19, p. 7.

${ }^{28}$ Ídem.

${ }^{29}$ Marshall, Tony, F. (1999), Restorative justice and overview, Home Office, London, p. 6.
} 
Christian Norberto Hernández Aguirre

Jessica Mendivil Torres

Cynthia Vedelí Hernández Aguirre

voluntariedad, a la decisión de las partes de llegar o no a un acuerdo, y explicando los alcances de aprobarse el mismo ${ }^{30}$.

Por lo que la intervención del facilitador a diferencia de un procedimiento judicial desde luego cumpliendo los requisitos que por ley se establecen, les pueden permitir a las partes hacer suyo el conflicto y decidir en su caso la forma de resolverlo, accediendo a que el resultado del proceso sea más efectivo y cumplible, terapéutico y porque no decirlo, educacional, logrando una mayor satisfacción de sus intereses. Todo esto se logra al poner en práctica, sea cual sea el mejor método que considere el facilitador, la teoría, herramientas, principios y, más aún, las mejores prácticas adquiridas dentro de los MASC.

Asimismo, en concordancia con Van Ness y Heetderks, son valores centrales de la justicia restaurativa:

El Encuentro: consiste en el encuentro personal y directo entre la víctima, el autor $u$ ofensor $y / u$ otras personas que puedan servir de apoyo a las partes y que constituyen sus comunidades de cuidado o afecto.

La Reparación: Es la respuesta que la justicia restaurativa da al delito. Puede con en restitución o devolución de la cosa, pago monetario, o trabajo en beneficio de la víctima o de la comunidad. La reparación debe ir primero en beneficio de la víctima concreta y real, y luego, dependiendo de las circunstancias, puede beneficiar a víctimas secundarias y a la comunidad.

La Reintegración: Se refiere a la reintegración tanto de la víctima como del ofensor en la comunidad. Significa no sólo tolerar la presencia de la persona en el seno de la comunidad sino que, más aún, contribuir a su reingreso como una persona integral, cooperadora y productiva.

La Participación o inclusión: Consiste en regalar a las partes (víctimas, ofensores y eventualmente, la comunidad), la oportunidad para involucrarse de manera directa y completa en todas las etapas de encuentro, reparación y reintegración. Requiere de procesos que transformen la inclusión de las partes en algo relevante y valioso, y que aumenten las posibilidades de que dicha participación sea voluntaria ${ }^{31}$

Podemos aducir que para lograr los valores centrales de la justicia restaurativa por medio de los MASC se hace necesario la presencia de un facilitador especializado en el que deba reunirse un perfil idóneo, filosofía y teoría del derecho contemporáneo, así como buenas o mejores prácticas ante la resolución de conflictos penales mediante los métodos alternativos. De acuerdo con Pesqueira y Abud, el derecho penal tutela valores cuya protección es indispensable para la convivencia social. Un sistema de justicia penal que opera eficientemente contribuye a garantizar la seguridad ciudadana y, en consecuencia, a reducir la criminalidad, factor indispensable para hacer efectiva la seguridad humana, ya que es una de las bases las que ésta última sustenta ${ }^{32}$.

Podemos deducir que la implementación bien llevada de los MASC y quienes la operan en nuestro sistema penal, apoya en todos los sentidos a la ansiada seguridad humana y no única-

\footnotetext{
${ }^{30}$ Del artículo 35 de la ley de MASC en materia penal se pueden desprender algunos de los alcances de los acuerdos como que se resolverá de inmediato sobre la extinción de la acción penal o el sobreseimiento del asunto, según corresponda. La resolución emitida por el Juez tendrá efectos de sentencia ejecutoriada. El incumplimiento del Acuerdo dará lugar a la continuación del procedimiento penal. En caso de cumplimiento parcial de contenido pecuniario éste será tomado en cuenta por el Ministerio Público para efectos de la reparación del daño.

${ }^{31}$ Véase Van Ness, Van Ness, Daniel, W. and Strong Heetderks, Kareen (1997), Restoring Justice, Anderson Pub Co, U.S.A, p. 37 en adelante.

${ }^{32}$ Pesqueira, Jorge y Abud, Amalia (2010), Mediación asociativa y cambio social. El arte de lo posible, editorial Universidad de Sonora, México, p. 83.
} 
mente el objetivo de intimidar con una pena o castigo a quien infringe alguna norma penal. Ante lo anterior, se abre en los artículos 17, párrafo cuarto, 18, segundo párrafo y Art. 21, párrafo noveno y décimo de la Constitución Federal, la obligación del Estado en colocar a los MASC como una opción más y para adolescentes ante un sistema integral de justicia penal en donde operen las formas alternativas de justicia y también la responsabilidad del Estado para establecer políticas públicas tendientes a la prevención del delito.

En palabras de Pesqueira, el diálogo es el eslabón crucial para que la relación entre los protagonistas del conflicto dé un giro de 360 grados, se reformule la visión de la misma y las posibilidades positivas frente al conflicto ${ }^{33}$. Quienes participan en algún procedimiento restaurativo aunado a los poderes, habilidades y cualidades del facilitador, debe permitirse que de resolverse o no el conflicto o parcialmente el mismo, se cree un espacio único para los protagonistas y se establezcan posibilidades o propuestas de solución con la guía de un facilitador, así como también, sea cual fuere el resultado, se busque que el acuerdo tenga efectos terapéuticos, educativos y sea cumplible.

\section{Los facilitadores y los delitos en que proceden los acuerdos reparatorios. Idoneidad y límites}

Como bien se ha mencionado, los acuerdos reparatorios son un mecanismo de negociación y solución del conflicto penal que permite la culminación del proceso penal previo acuerdo entre el imputado y el agraviado, permitiendo que el imputado sea beneficiado con la abstención de la acción penal por parte del fiscal y el agraviado con la satisfacción del pago de la reparación civil $^{34}$. Ahora bien, como ya se sabe, una de las finalidades de los acuerdos reparatorios es la de evitar la judicialización de los asuntos, esto es, que con los mecanismos alternativos normados logremos evitar llevar un proceso a los tribunales y que por estos medios las partes logren llegar a un arreglo en el que ambas se sientan satisfechas con la manera en que se solucionó el conflicto.

$\mathrm{Al}$ acuerdo reparatorio se le ha identificado dentro de la legislación como de solución alterna y terminación anticipada de un hecho, esto es, que podríamos denominarla como una forma nueva de concluir un asunto penal, pues dentro del nuevo modelo de justicia penal se considera como una vía exitosa de concluir un procedimiento, sin necesidad de llegar al juicio oral. Y mayor éxito tendrá si éste se resuelve a satisfacción de los participantes, como lo son, la víctima y el imputado, pues para llegar a esta conclusión del procedimiento, las partes deberán estar de acuerdo y satisfechos con el resultado, pues ambos se verán favorecidos con la solución pronta y sobre todo que va a satisfacer sus requerimientos y necesidades. Un acuerdo reparatorio que satisfaga las pretensiones de la víctima y el imputado es sumamente atractivo dentro de un proceso, pues cabe el riesgo que en caso de continuar con el procedimiento, el resultado sea contrario a los intereses de uno u otro.

A raíz de la reforma del año 2008 en la que se contempló dentro de la constitución federal los MASC, a través de los cuales se vale de la mediación, conciliación y entre ello la negociación para facilitar que el imputado y la víctima puedan llegar a una solución, es que los acuerdos reparatorios pueden tener éxito, pues es precisamente a través de dichas herramientas que se valen para llegar a éste resultado. Para ello, en diciembre del 2014 se publica la Ley Nacional de

\footnotetext{
${ }^{33}$ Ibídem, p. 193.

${ }^{34}$ En el Ministerio de Justicia y Derechos Humanos de Perú (2014), Protocolo de Acuerdo Reparatorio, Perú, p. 1, [en línea] disponible en: https:/scc.pj.gob.pe/wps/wcm/connect/208c8400443d4d8f8fcadfeb309de3e9/Protocolo $+\mathrm{de}+$ acuerdo+reparatorio.pdf?MOD=AJPERES\&CACHEID=208c8400443d 4d8f8fcadfeb309de3e 9
} 
Mecanismos Alternativos de Solución de Controversias en Materia Penal, en la que se contempla a la justicia restaurativa a través de una posible conciliación, mediación y junta restaurativa.

Dentro del artículo tercero de la Ley Nacional de Mecanismos Alternativos de Solución de Controversias, se precisa entre otros términos, en el artículo $3^{\circ}$, fracción $\mathrm{V}$, el termino de facilitador, de la siguiente manera: El profesional certificado del Órgano cuya función es facilitar la participación de los intervinientes en los Mecanismos Alternativos ${ }^{35}$. Ahora bien, dentro de la misma normatividad, en su artículo 48 , se expresa cuáles son los requisitos para ser facilitador ${ }^{36}$, señalando que para ser uno de ellos se deberá de contar con el grado de licenciatura y cédula profesional afín a las labores que desarrollarán. Sin embargo, no se especifica alguna profesión con la que deba contar aquella persona que se encuentre como facilitador, lo que implica que es muy amplia la gama de posibilidades de profesión. Al mencionar la normatividad que uno de los requisitos es que la profesión debe ser afín ¿podemos entender que la profesión del facilitador será afín al conflicto de las partes?

Consideramos que dejar de manera abierta la interpretación de una profesión para cubrir el perfil de un facilitador podría traer diversos conflictos, pues quizá la persona que esté a cargo del conflicto no tendrá la experiencia ni la visión o bien la capacidad para lograr prevenir o pretender que no se violen conductas de otro tipo, con ello, otros derechos e inclusive, obstaculizar principios de los MASC o el tiempo para su mejor resolución; aunque en el artículo 34, fracción VII, se exprese que el acuerdo será validado por un licenciado en derecho.

Por otro lado, en relación con lo que señala el CNPP respecto a los acuerdos reparatorios, resulta importante mencionar que dentro de dicha normatividad, en efecto, se habla del mismo (Arts. 186-19o) así como de que las autoridades (refiriéndose al Ministerio Público y al Juez de Control) que podrán invitar a las partes a la realización de un acuerdo reparatorio para resolver el conflicto, haciéndose llegar de los mecanismos alternativos para la solución de conflictos ya sea a través de la negociación, conciliación o mediación, siempre y cuando sea cubierta la reparación del daño y la víctima esté de acuerdo. Sin embargo, en el artículo 190 del Código, se señala que los acuerdos reparatorios deberán ser aprobados por el Juez de Control o por el Ministerio Público, según la etapa en la que se encuentren, lo que implica que en un inicio no son éstos quienes se ven involucrados para llegar a un acuerdo justo, por así mencionarlo, sino que únicamente velarán por los intereses de las partes aceptando o no el acuerdo al que éstos se hayan hecho llegar. Sin mencionar la ley a donde deberá recurrir para formular dicho acuerdo reparatorio.

Por otro lado, para la celebración de dicho acuerdo reparatorio, es importante señalar que sólo podrán celebrarse en los siguientes casos:

1. Delitos que se persiguen por querella, por requisito equivalente de parte ofendida o que admiten el perdón de la víctima o el ofendido;

\footnotetext{
${ }^{35}$ Ley Nacional de Mecanismos Alternativos de Solución de Controversias en materia penal. Actualizada a 29 de diciembre de 2014.

${ }^{36}$ Artículo 48. Ley de Mecanismos Alternativos de Solución de Controversias en materia penal.Los Facilitadores deberán:

I. Poseer grado de Licenciatura afín a las labores que deberán desarrollar, con cédula profesional con registro federal;

II. Acreditar la certificación que establece esta Ley;

III. Acreditar las evaluaciones de control de confianza que establecen las disposiciones aplicables para los miembros de instituciones de procuración de justicia;

IV. No haber sido sentenciados por delito doloso, $y$

$V$. Los demás requisitos que establezca esta Ley y otras disposiciones que resulten aplicables.
} 


\section{Delitos culposos, o}

3. Delitos patrimoniales cometidos sin violencia sobre las personas ${ }^{37}$.

Una vez que ya haya sido aprobado el cumplimiento de las obligaciones que contrajeron las partes, el juez decretará la extinción de la acción penal teniendo el carácter de una sentencia absolutoria ejecutoriada. Sin embargo, como se mencionó, el Juez de control o el Ministerio Público verificarán que las obligaciones que se contraen no sean notoriamente desproporcionadas y que las partes estuvieron en condiciones de igualdad para negociar y que no hayan sido obligados a llegar a dicho acuerdo.

El llegar a un acuerdo reparatorio tiene ciertas características que podemos resaltar, tales como:

a) Nos brinda la posibilidad de terminar con un proceso de manera anticipada, siempre que se haya cubierto la reparación del daño, lo que a la víctima le brinda una seguridad en cuanto al daño patrimonial causado, que éste será resarcido.

b) La reparación del daño que se llegue acordar será lo que el imputado cubrirá como tal, sin importar que realmente ese sea el monto total que se dañó, esto es, se cubrirá lo acordado y, quizá, no lo que se dañó a causa de la conducta cometida.

c) El Código Nacional de Procedimientos Penales, en el artículo 190, tal y como se mencionó, señala que será el Juez de Control o el Ministerio Público, quien apruebe el acuerdo reparatorio al que hayan llegado las partes, acuerdo en el que se presupone que se ejerció unos de los principios de los MASC, como lo es la voluntariedad, por lo que, si las partes llegaron a un acuerdo, las autoridades deberían de aceptarlo como tal. Sin embargo, aquí se señala que cuando éstos consideren que el mecanismo no se desarrolló conforme la ley, entonces no será autorizado, por lo que esto culminaría con una sentencia condenatoria. Quizá lo que las partes desde un principio desearon no obtener y por ese motivo habían seleccionado el acuerdo reparatorio. Ahora la interrogante también es, ¿de qué manera la autoridad podrá determinar que el mecanismo alternativo no fue desarrollado conforme a la ley, si estos no estuvieron presentes en el mismo?

Como lo señala Claus Roxin ${ }^{38}$, el seleccionar esta clase de mecanismos, más allá de buscar un fin legítimo que es situar al interés de la víctima u ofendido como una prioridad, genera también una desigualdad en la negociación ya que el proceso se verifica en contra del imputado que incluso puede estar restringido de forma absoluta o relativa de su libertad y otra basada en el factor económico, ya que estarán en condiciones de aceptar dicha figura aquellos imputados que cuenten con una mayor solvencia económica, pues para quienes se encuentren en una posición económica en desventaja será muy complicado acceder a dicho beneficio procesal.

\section{Conclusiones}

Primera. Para la solución de controversias no solo jurídico-penales se debe pretender un mínimo de violencia y un máximo de libertades, por lo que el empleo de los MASC en materia

\footnotetext{
37 Artículo 187 del Código Nacional de Procedimientos Penales. Actualizado a 17 de junio de 2016.

${ }^{38}$ Roxin, Claus et al. (2015), Perspectivas y retos del Proceso Penal, Universidad Pontificia Bolivariana, Colombia, p. 369.
} 
penal pueden ser utilizados, entre otros fines, para ser un medio más para materializar, entre otros principios del derecho penal, el de intervención mínima en favor de una justicia restaurativa y no solo una retribucionista, así como para la materialización de derechos fundamentales como al contribuir a generar una reparación del daño integral e inserción o reinserción social en cualquier etapa de un proceso judicial o antes del mismo.

Segunda. El perfil idóneo, especialización, capacitación y experiencia adecuada de los facilitadores se relacionan directamente con la mejor funcionalidad de los MASC e impacto de soluciones generadas a través de los mismos, donde se requiere el funcionamiento de un órgano que garantice su seguimiento con lo que se puedan cualificar sus beneficios de mejor manera y en coordinación con las diversas autoridades que puedan intervenir.

Tercera. La precisión en cuanto a la profesión afín a los MASC se hace necesario para su mejor impacto, desarrollo y mejor solución ante un conflicto en que voluntariamente participen las partes, como lo son, la víctima-victimario y en su caso la comunidad afectada, asimismo, que se garantice que quien atienda a las partes tenga conocimientos jurídicos, además del perfil idóneo, condiciones y habilidades para su mejor progreso.

\section{Fuentes de información}

\section{A) Bibliografía}

Aguiló Regla, Josep (2015), El arte de la mediación. Argumentación, mediación y negociación, Trotta, Madrid.

Esparza Martínez, Bernardino (2015), La reparación del daño, INACIPE, México, D. F.

Fried Schnitman, Dora (comp. 200o) Nuevos paradigmas en la resolución de conflictos. Perspectivas y prácticas, Ediciones Granica S. A. Buenos Aires, Argentina.

Marshall, Tony, F. (1999) Restorative justice and overview, Home Office, London.

Marchiori, Hilda (coord., 2007), Principios de Justicia y Asistencia para las Víctimas. Estudios sobre la Victimización editorial Encuentro, Argentina.

Moreno Vargas, Mauricio (2010), Nuevo Sistema de Justicia Penal para el Estado de México, Porrúa, México, D. F.

Pacheco Pulido, Guillermo (2015), Mediación. Cultura de paz, medio alternativo de administración de justicia, Porrúa, México, $3^{\mathrm{a}}$ ed.

Pesqueira, Jorge y Abud, Amalia (2010), Mediación asociativa y cambio social. El arte de lo posible, editorial Universidad de Sonora, México.

Roxin, Claus et al (2015), Perspectivas y retos del Proceso Penal, Universidad Pontificia Bolivariana, Colombia.

VAn Ness, Van Ness, Daniel, W. and Strong Heetderks, Kareen (1997) Restoring Justice, Anderson Pub Co, U.S.A. 


\section{B) Hemerografía}

Hernández Aguirre, Christian Norberto et al (2015) "Importancia de los métodos alternativos de solución de controversias en materia penal en México" Revista Ciencia Jurídica, Año 4, No. 7, Universidad de Guanajuato, México.

\section{C) Normatividad}

Código Nacional de Procedimientos Penales. Actualizado a 17 de junio de 2016.

Ley Nacional de Mecanismos Alternativos de Solución de Controversias en Materia Penal. Actualizada a 29 de diciembre de 2014 .

Ley Nacional de Ejecución de Sanciones Penales. Actualizada a 16 de junio de 2016.

Ley Orgánica 10/1995, de 23 de noviembre, del Código Penal de España.

D) INTERNET.

Cid Moliné, José (2009) “Medios alternativos de solución de conflictos y derecho penal”, en Revista Estudios de la Justicia, No. 11, Chile. En línea. Disponible en: http://web.derecho. uchile.cl/cej/ rej11/CID\%20_11_.pdf

Comisión de Derechos Humanos del Distrito Federal (2010) Revista de Derechos Humanos, número 12, año VIII. En línea. Disponible en: http://cdhdf.org.mx/wp-content/ uploads/2014/o5/dfensor_12_2010.pdf

Domingo de la Fuente, Virginia (2017) “Aproximación a la justicia restaurativa”. En línea. Disponible en: https://ddd.uab.cat/pub/eciejur/eciejur_a2017n1/eciejur_a2017n1a3.pdf. Fecha de consulta 18 de marzo de 2017.

Justicia restaurativa y mediación penal, p. 14. En línea. Disponible en: http://www. justiciarestaurativa.org/news/justicia-restaurativa-y-mediacion-penal. Fecha de consulta 21 de marzo de 2017 .

Ministerio de Justicia y Derechos Humanos de Perú (2014) Protocolo de Acuerdo Reparatorio, Perú. En línea. Disponible en: https://scc.pj.gob.pe/wps/wcm/connect/208c8400443d4d $8 \mathrm{f} 8 \mathrm{fcadfeb} 309 \mathrm{de}$ e9/Protocolo+de+acuerdo+reparatorio.pdf?MOD=AJPERES\&CACH $\mathrm{EID}=208 \mathrm{c} 8400443 \mathrm{~d} 4 \mathrm{~d} 8 \mathrm{f} 8 \mathrm{fcadfeb} 309 \mathrm{de} 3 \mathrm{e}$

Mondragón-Lasagabaster, Jasone (2012) "La Mediación en el Ámbito Penal/Criminológico. Tema 7. Habilidades y estrategias de comunicación en el proceso de mediación (curso 2012-2013), Universidad de Alicante, pp. 1-15. En línea. Disponible en: http://rua.ua.es/ dspace/handle/10045/25661

Oficina de las Naciones Unidas contra la Droga y el Delito (2013) Guía de introducción a la prevención de la reincidencia y la reintegración social del delincuentes, Serie de Guías de Justicia Penal, Nueva York. En línea. Disponible en: https://www.unodc.org/documents/ 
Christian Norberto Hernández Aguirre Jessica Mendivil Torres

Cynthia Vedelí Hernández Aguirre

justice-and-prison-reform/UNODC_SocialReintegration_ESP_LR_final_online_version.pdf. Fecha de consulta 11 de mayo de 2017.

Olalde, Alberto (2006) Justicia Restaurativa y mediación en el ámbito penal. Apuntes Máster de mediación familiar y social de la Universidad de Murcia, p. 6. En línea. Disponible en:http://servicios.educarm.es/templates/portal/ficheros/websDinamicas/102/APUNTES\%20ALBERTO\%20OLALDE\%5b1\%5d\%5b1\%5d_1.pdf

Organización de las Naciones Unidas, Manual sobre programas de justicia restaurativa, Naciones Unidas, Nueva York, 2006, serie de manuales sobre justicia penal, p. 8. En línea. Disponible en: https://www.unodc.org/documents/justice-and-prison-reform/Manual_ sobre_programas_de_justicia_restaurativa.pdf. Fecha de consulta 21 de marzo de 2017.

Pastor Seller, Enrique y Huertas Pérez, Elena "La mediación penitenciaria como método alternativo de resolución de conflictos entre internos en el ámbito penitenciario”, en Revista Entramado, vol. 8, núm. 2, julio-diciembre, 2012. En línea. Disponible en: http:// www.redalyc.org/articulo.oa? $\mathrm{id}=265425848009$

\section{E) Jurisprudencia}

Corte IDH, Caso González y Otras (“Campo Algodonero”) vs. México.

Semanario Judicial de la Federación, https://sjf.scjn.gob.mx/sjfsist/Paginas/tesis.aspx 